\section{Visión Electrónica \\ Más que un estado sólido}

https://revistas.udistrital.edu.co/index.php/visele
UNIVERSIDAD DISTRITAL

FRANCISCO JOSÉ DE CALDAS

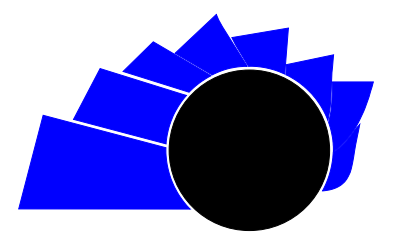

VISIÓN ELECTRÓNICA

\title{
Linear algebra learning focused on plausible reasoning in engineering programs
}

\section{Aprendizaje del algebra lineal centrado en el razonamiento plausible en carreras de ingeniería}

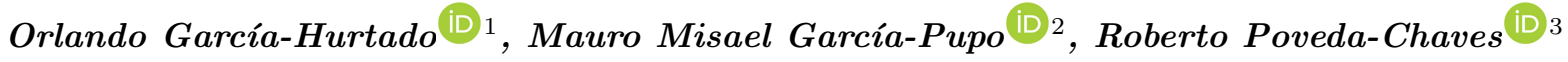

\section{INFORMACIÓN DEL ARTÍCULO}

Historia del artículo:

Enviado: 25/02/2019

Recibido: 17/03/2019

Aceptado: 12/04/2019

\section{Keywords:}

Didactic model

Linear Algebra

Methodological strategy

Plausible reasoning

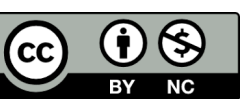

\section{Palabras clave:}

Modelo didáctico

Algebra lineal

Estrategia metodológica

Razonamiento plausible

\begin{abstract}
A methodological strategy is proposed for the teaching of Linear Algebra in engineering programs focused on plausible reasoning. These concepts were developed by [1] and [2], through the formulation and adaptation of interesting problems, whose design admitted a didactic model and a methodological procedure for the generation of conjectures through the mediation of technology and geometric visualization as key factors in the construction of the main concepts of the discipline by the students. The difficulties in the teaching and learning of Linear Algebra have been studied since last century, in particular since the nineties. The LACSG (Linear Algebra Curriculum Study Group) in the USA is a reference point. On the other hand, Anna Sierpinska and Jean-Luc Dorier lead another group in Canada and Europe. Both groups coincide that one of the greatest problems in the teaching and learning of Linear Algebra is the formal approach of the classes that are traditionally taught. The starting point of this study is the great difficulties students experience when assimilating definitions, theorems and demonstrations, which are elusive for the future engineers.
\end{abstract}

\section{RESUMEN}

Se propone una estrategia metodológica para la enseñanza del álgebra lineal en carreras de ingeniería centrada en el razonamiento plausible conceptos desarrollados por [1] y [2], a través de la formulación y adaptación de problemas no rutinarios cuyos diseños admitan un modelo didáctico y un procedimiento metodológico para la generación de conjeturas a través de la mediación de la tecnología y la visualización geométrica como factores fundamentales en la construcción de los principales conceptos por parte de los estudiantes y que caracterizan esta disciplina. Las dificultades de la enseñanza y aprendizaje del álgebra lineal se vienen investigando desde el pasado siglo, en particular en la década de los noventas; es referente el grupo LACSG (Linear Algebra Curriculum Study Group) en los Estados Unidos. Por otra parte, Anna Sierpinska y Jean-Luc Dorier lideran otro grupo en Canadá y Europa. Ambos grupos coinciden que uno de los grandes problemas en la enseñanza aprendizaje del Álgebra Lineal es el enfoque formal de las clases que tradicionalmente se imparte. Por tanto, es el punto de partida de este estudio que estudiantes de primer o segundo semestre experimentan gran dificultad en asimilar las definiciones, teoremas, y demostraciones, las que resultan poco asequibles para los futuros ingenieros.

\footnotetext{
${ }^{1}$ BSc. In Mathematics, Universidad Distrital Francisco José de Caldas, Bogotá, Colombia. Ph.D. In Mathematics Education. Current position Professor at Universidad Distrital Francisco José de Caldas, Colombia. E-mail: ogarciah@udistrital.edu.co

${ }^{2}$ BSc. In Mathematics, Ph.D. In Mathematics, Universidad de la Habana, Cuba. Current position: Professor at Universidad Antonio Nariño, Bogotá, Colombia. E-mail: mauro@uan.edu.co.

${ }^{3}$ BSc. In Mathematics, Universidad Nacional de Colombia, Colombia. MSc. In Systems Engineering, Universidad Nacional de Colombia, Colombia. Ph.D. (c) In Systems Engineering, Universidad Nacional de Colombia, Colombia. Current position: Professor at Universidad Distrital Francisco José de Caldas, Colombia. E-mail: rpovedac@udistrital.edu.co.
} 


\section{Introduction}

In mathematics courses in higher education there is not a lot of space for plausible reasoning development in the implementation of classes [3] has been pondering about this situation and its importance in mathematics education. What has been said applies to a traditional Linear Algebra class, as the space for teaching and learning where the student does not experience active methods in the construction of his knowledge from the argumentative point of view of the contents and, therefore, there is a lack of appreciation of other ways of validation, since the only one presented is the one of the professor.

One of the main problems of the teaching of vector spaces lies on the formal approach [2]; that has been concluded by many studies on the teaching of Linear Algebra. While some studies have tackled the problem from the intuitional didactic point of view $[4,5]$, and others have used the geometric point of view [6], some researchers state that the problem is semiotic in nature, since the students are presented with the definitions formally, without having cleared some semantic aspects in them. Some others say that the problem is that students have weak formal logic bases and that makes the understanding of the concepts difficult [7]. But one of the most prolific authors on the theme, Jean-Luke Dorier [5], maintains that there is not a unique valid way to solve the problem, since the cognitive processes of math are too complex, therefore, these difficulties must help the professor perform a richer, more expert teaching with more flexibility, which is the objective of this study.

These considerations further the research on the difficulties of Linear Algebra teaching and learning in engineering programs, and, based on them, a methodological proposal is posited, supported on a didactic model based on plausible reasoning, the use of technology and geometric visualization, with activities that allow the solution of non-routine Linear Algebra problems under the approach in which they are integrated.

\section{Research problem}

It can be expressed through the question: How to affect different factors that influx negatively the betterment of Linear Algebra teaching and learning process? This question is inferred from this contradiction pair $[7,8]$ (Figure 1)
Figure 1: External contradiction that clarifies the research problem, [8].

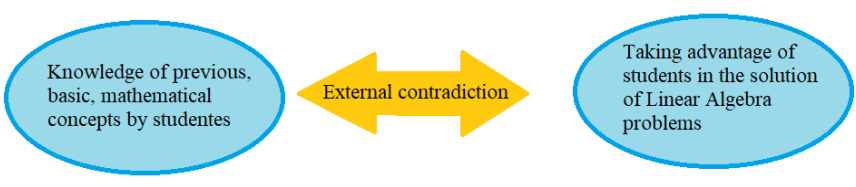

\section{Methodology}

This study was developed under a qualitative approach and the theoretical bases of action- research, whose main aim is to better the quality of an action, in this case of education, through theoretical and practical advances. The main characteristic of this action-research is its development as a spiral model that includes diagnostic, planning, action, observation and reflection.

\subsection{Study domain}

The study is made with all engineering students and the sample was taken from Francisco José de Caldas University. These students take the class in their second semester; it has no prerequisites. They study electronic, electrical, systems, industrial and cadastral engineering. Students come mainly from low to middle social classes and from public schools.

\subsection{General research outline}

This investigation was developed in three stages, namely:

Stage I. Study design. The concrete tasks for this stage were:

a. Description of diverse studies related with the objectives and the problem posited for this study

b. Collection and analysis of the syllabi of Linear Algebra of national and international universities

c. Theoretical support of plausible reasoning and any other required area

d. Design and implementation of the Linear Algebra course

e. Design and implementation of diagnostic tests

f. Teachers and students surveys

g. Activities design

h. Didactic model and procedures design

i. Students' attitude survey 
Stage II. Study implementation. In this stage, the proposed activities are implemented with the objective of observing and recording their development by the students in the classroom. In this stage, one can find the following tasks:

a. Development and application of the proposed activities

b. Implementation of the procedure and didactic model

c. Application of a final test or survey

Stage III. Learning process analysis. This is related to the results found, after carrying out all the implementation. It was made using case studies. The tasks were:

a. Organization and analysis of students' activities

b. Organization and analysis of the students' survey answers

c. Assessment of the didactic model for its validation through the use of expert criteria

\subsection{Didactic model}

The didactic model presented in this study is based on the quasi-empirical school of mathematics, lead by Lakatos and Polya, with cognitive and learning support based on constructivism and cognitive reflection, but also on geometric visualization and the use of technology as a didactic tool.

The didactic models are closely linked with education sciences teaching - learning, each with a particular interest on the researcher's idea of teaching. For instance, the researcher assumes a didactic model position that is coherent and that is based on the teaching -learning of mathematics, particularly with Linear Algebra in engineering programs; thus, it is assumed that: " $a$ didactic model is an abstraction of the teaching and learning process that can be adjusted to any type of science, that accepts the reference frameworks of didactic and pedagogy that, theoretically supported, allow for the interpretation and establishment of new relations to perfect the process". [7].

The model has four main interrelated parts. First, we have the theoretical foundation of Linear Algebra. Second, we have the diagnostic that was carried out at the beginning of the study, which allows the generation of a model that approximates a possible solution to the problem through a methodological process based on plausible reasoning and in a particular software as technological tool. This is formed by two processes, the instrumentalization, that allows to explore each software command with the previous knowledge of students, and the instrumentation, that has to do with the practical application of those commands in the solution of the problems that form part of a given activity. Both processes are known as instrumental mediation.

The mediating elements constitute the third part, they are factors that must accelerate the solution of the contradictions, both internal and external; that is performed with the application of a heuristic procedure in its practical implementation, as the fourth and last part.

This model starts from the integration of systematized elements in the theoretical support, within which lies the solution of the problem as and didactic methodological support. The instrumental mediation is a part of the learning cognitive levels through the resources of a software, in this case, Geogebra.

\section{- The principles of instrumental mediation}

Cognitive flexibility, associative fluency, and problem solving are the factors that integrate the dimension of the didactic model and that act as accelerators of the solution of the contradiction, those are the ones that give sense to and, at the same time, solve the problem.

\section{- Formal structure of the didactic model}

The formal structure of the didactic model includes premises, dynamizing elements and phases.

\section{- Premises of the didactic model.}

In the context of this research, a premise is understood as the systematized theoretical foundation explained in the previous paragraphs that serve as the basis for the model. The premises are: the theoretical referents in the teaching and learning processes of Linear Algebra from the perspective of the sciences and the solution of problems through the use of software. Instrumental mediation as a cognitive act mediated by Geogebra allows the student to visualize the figure, associate the concept and acquire the knowledge for his education as a future engineer. In sum, instrumental mediation as a transversal element in the process of solving non-routine problems should allow the student, through visualization, to justify a conjecture associated to the solution of a problem or question of each one of the activities. 
Next, it will be explained how these theoretical referents work in the context of the model.

In the model, the idea of a multilateral approach of these criteria is emphasized. The model posits that the relations that take place in the framework of the programmed activities for students and the organization are of an epistemic nature and reflect the essence and reciprocity of the contents. Considering the solution of the problems through the use of questions that generate conjectures as a theoretical reference in the development of Linear Algebra teaching- learning process implies a change in the way of thinking facing all the problems of knowledge; besides, it presupposes an explanatory frame of reality as a whole, supported by the establishing of shared links and new relations that generate new logical procedures that guarantee the integrated search for information when undertaking a specific content through the process. Here is where each student formulates conjectures as an essential part of the solving of the problem, which should differentiate him from someone immersed in a conventional teaching and learning process.

The idea of problem solving as a theoretical reference of the teaching learning process dynamizes the relations that can be established between the different disciplines in the area and those with the technological resources in the solving of teaching problems, and it is contextualized in the same way in which the essence of each studied content is understood in a more integrating frame, so it becomes an essential element that compromises and involves the subjects in the active apprehension of knowledge, values, habits and ways of acting in the construction and justification of conjectures.

\section{- Dynamizer Elements}

In the proposed didactic model, the dynamizing elements (or contradiction accelerators) are understood as the theoretical components that start in the systematization of the existing scientific contents, enriched or created, and that move the model and constitute the transversal elements. Those transversal elements are: instrumental mediation, and with it, non-routine problem solving as a way to better students' Linear Algebra learning.

a. Instrumental mediation: this transversal element allowed, in the research process, to mediate in the knowledge of students, once they interacted with Geogebra to solve the difficulties presented in the initial diagnostic; that is, the scientific contribution was present in the cognitive act mediated by the software. b. Problem resolution: this element functioned as the traditional teaching- learning based on routine problems breaking point.

The transversality in the model context surpasses widely the limit of Linear Algebra teaching - learning in engineering programs, by including cognitive flexibility and associative fluency in the construction and justification of conjectures with the use of a software for the Linear Algebra problem solving process.

- The didactic model for the teaching of Linear Algebra focused on plausible reasoning

In the external contradiction of Figure 1, one can observe that the research object is out, that is the Linear Algebra teaching-learning process; however, it allowed, through an epistemic reflection another contradiction that belongs to the internal object that is being researched, and that is characterized by the internal nature of it (Figure 2 and 3 ).

Figure 2: Internal contradiction in the research problem [8].

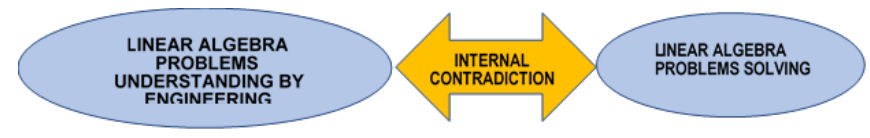

With a methodological process given by (Figure 4).

This process is based on:

\section{- Learning by Questions}

The learning process must be active, where students can construct new concepts and ideas, therefore, the professor must provide problem situations through well-constructed questions so that the student discern by himself the concepts that have been posited as objectives $[5,6]$.

It is considered that the activities design must be made taking into account a set of questions carefully made in order for the student to obtain answers that take him to the ideas that must be interiorized.

A positive aspect that has an influence in the choosing of this approach is a better attitude of the students, since this approach is more student centered, so it allows for a more active participation in the acquisition of concepts, it also helps develop critical thinking and, besides, it develops the ability to solve problems and, therefore, create more skills in the development of mathematical processes. 
Figure 3: Graphic representation of the didactic model focused on plausible reasoning [8].

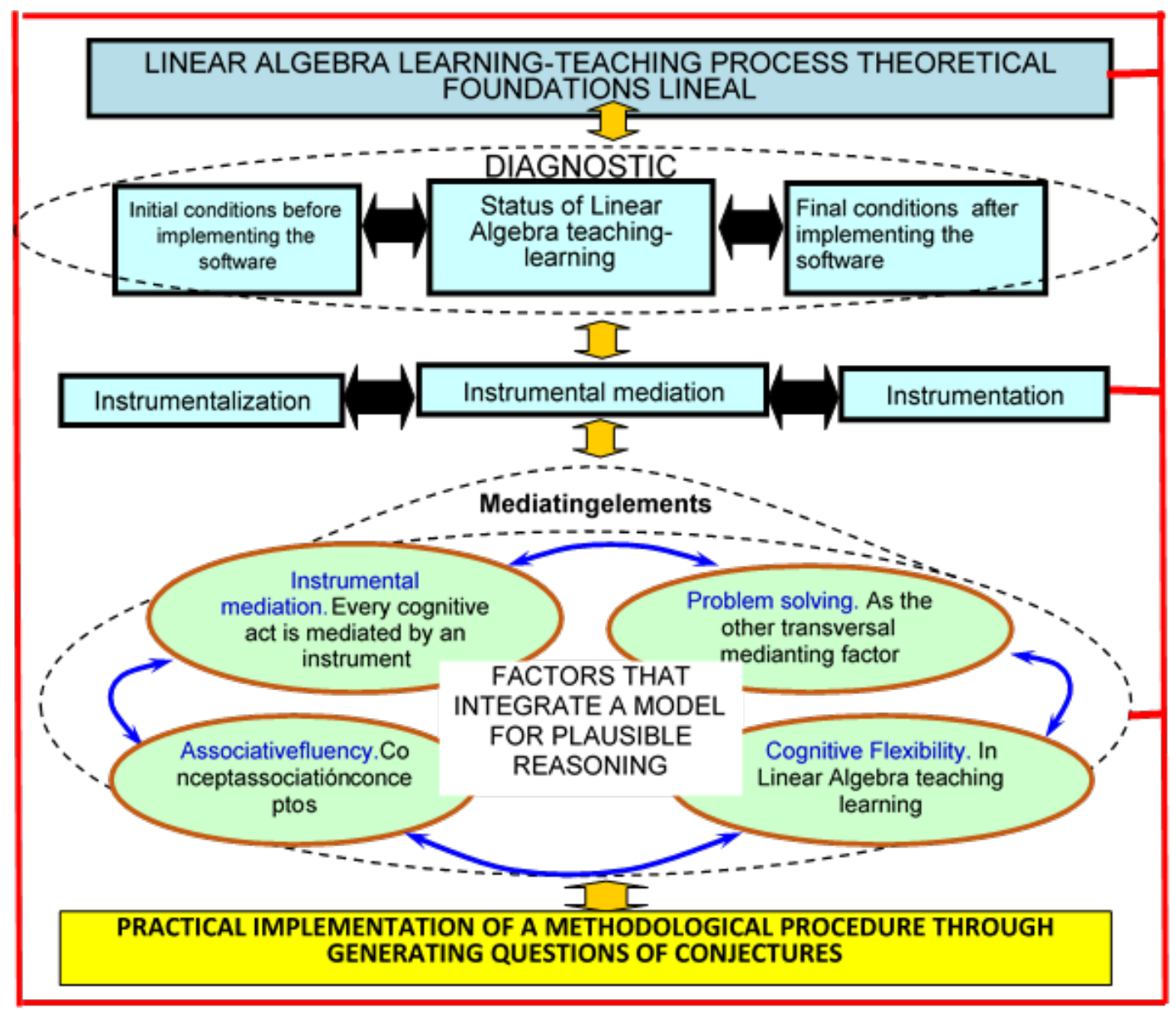

Figure 4: Implementation procedure for learning supported on plausible reasoning, technologies and visualization in the solution of Linear Algebra problems [8].

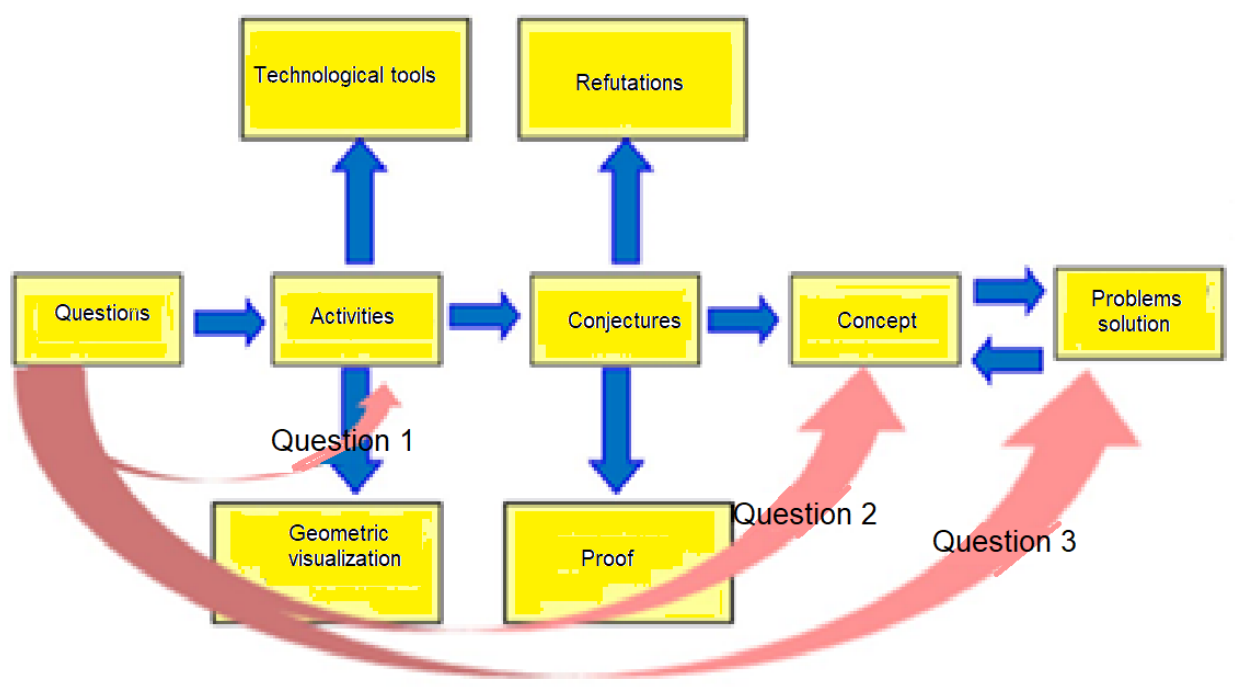




\section{- Question Levels}

First level. They are basic questions where one seeks to search for information as to how the students are so that they can be introduced in the theme. Example (Figure 5)

Figure 5: Level 1 problem graph [8].

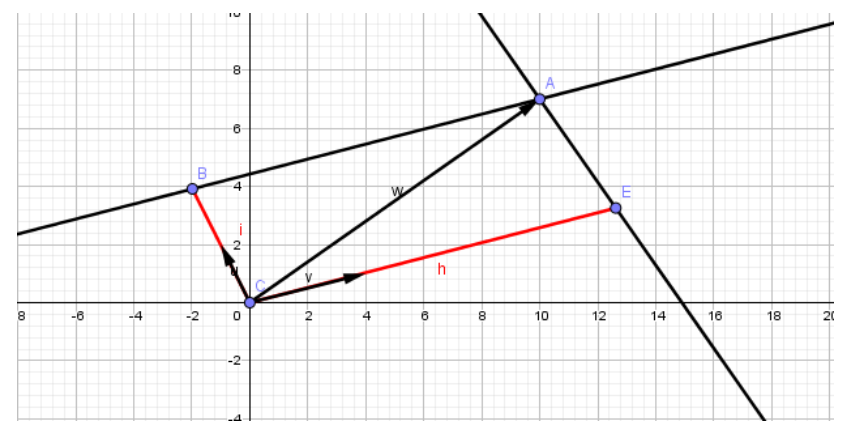

Vector $w=(10,7)$ is illustrated as a 'combination' of vectors $u=(-1,2)$ and $v=(4,1)$. How can vector $\mathrm{w}$ be expressed in an algebraic form?

Second level. Questions that imply the students' experience, confront and explore properties or concepts and/or take them to conjectures that must be proven or refuted.

Example:

Given the linear system

$$
\left\{\begin{array}{l}
2 x-y=3 \\
4 x-2 y=t
\end{array}\right.
$$

a. Determine if there is any value of $t$ so that the system has only one solution. (Use visualization for different values of $t$ ).

b. Determine a value of $t$ so that the problem has an infinite number of solutions.

c. For what $t$ values the problem has no solution?

d. Give a geometric interpretation of the previous questions. [9]

Third level. Questions where the student must apply the learned concept in practice, that is to say, in the solution of non-routine problems.

\section{Example}

What would you have to know about a solution set of a system of 26 linear equations with 30 variables to ensure that every non-homogeneous equation associated has a solution? [10].

\section{- Model Implementation}

The work was developed with 36 students class from the School of Engineering of District University 12 groups of 3 students were organized. The topics dealt with in the implementation were: Linear equations systems, matrixes, determiners, vectors, vector spaces and subspaces, linear independence, bases and dimension, range and nullity. For each theme, some theoretical orientations were given first. In the following class, they worked in groups the activities composed by problems with diverse levels of difficulty and applications to engineering that make students explore, analyze, conjecture and prove properties of the theme through plausible reasoning. The solutions given by the students were socialized in the following class.

\section{Results}

When finishing each of the activities, an assessment table with the groups' results is presented, in which the mode is taken as the measurement of central tendency to evaluate the effectiveness of the set of problems that made part of each of the activities in each one of the 12 groups.

Below, in Table 1, a summary of the solutions to each problem solved by each group is presented. These are the abbreviations used: (MB) for a complete and correct solution, (B) for a partial but correct solution, (R) for a solution that the group thinks that is complete but that is not totally correct, and (M) for a totally incorrect solution or an unsolved problem.

These results are a proof that the model and the methodological procedure proposed for Linear Algebra teaching through plausible reasoning, technology and visualization was an adequate method for the development of this course in the engineering programs. Besides, the drop-out rate decreased considerably compared with previous semesters and with other courses taught in the School of Engineering where the study was conducted.

\section{On the final student survey}

A survey and an interview were conducted with students on the methodology used in the development of the course. In the survey, the following criteria were used: TA, totally agree; A, agree; N, not in agreement or disagreement; D, disagree; TD, totally disagree. This is shown in the Table 2 
Table 1: Summary of the general effectiveness of the study, by groups.

\begin{tabular}{|l|l|l|l|l|l|l|l|l|l|l|l|l|l|}
\hline \multirow{2}{*}{ Activities } & \multicolumn{10}{|c|}{ Modes for each of the groups } \\
\cline { 2 - 15 } & G1 & G2 & G3 & G4 & G5 & G6 & G7 & G8 & G9 & G1000 & G11 & G12 & Mode \\
\hline $\mathrm{N}^{\circ} 1$ & MB & MB & MB & MB & MB & MB & MB & MB & MB & MB & MB & B & MB \\
\hline $\mathrm{N}^{\circ} 2$ & MB & MB & MB & MB & MB & MB & M & MB & MB & B & MB & B & MB \\
\hline $\mathrm{N}^{\circ} 3$ & MB & MB & MB & MB & MB & MB & M & MB & B & M & MB & R & MB \\
\hline $\mathrm{N}^{\circ} 4$ & MB & MB & MB & MB & MB & MB & R & B & MB & B & MB & B & MB \\
\hline $\mathrm{N}^{\circ 5}$ & MB & MB & MB & MB & MB & M & B & B & R & B & B & B & MB \\
\hline $\mathrm{N}^{\circ} 6$ & MB & MB & MB & MB & MB & B & B & B & B & MB & B & MB & MB \\
\hline $\mathrm{N}^{\circ} 7$ & MB & MB & MB & MB & MB & MB & B & B & R & R & B & B & MB \\
\hline $\mathrm{N}^{\circ} 8$ & MB & MB & B & MB & MB & B & B & R & MB & B & B & B & B \\
\hline Tendency & MB & MB & MB & MB & MB & MB & B & B & MB & B & MB & B & MB \\
\hline
\end{tabular}

Source: own.

Table 2: Appreciation of the students.

\begin{tabular}{|l|}
\hline 1-The methodology developed in this course implies a better understanding of \\
\hline 2-The level of difficulty of the problems was adequate \\
\hline 3- The time to develop each activity as sufficient \\
\hline 4- The methodology developed is different to the one traditionally used in \\
\hline 5- The methodology used is more motivating \\
\hline 6- The methodology makes you discover and conjecture Linear Algebra \\
\hline
\end{tabular}

Source: own.

In general terms, students answer that they liked learning by discovering through problem solving, because in that way they could make more sense of the themes covered in class. Besides, the use of technology and visualization was appealing to them, since it helped them better understand the concepts and avoided long and painstaking calculations.

The results obtained in these surveys can be classified in the following manner.

\section{- Attitude of the Students}

In terms of the answer to question five of the survey, where it is asked if the used methodology is more motivating, the results are shown in the Figure 6.

The results evidence that more than $75 \%$ of the students agreed that the methodology developed was motivating and it was experienced in that way in each of the classes.

\section{- About the conjectures}

In the final survey, in question six: The methodology used in the course takes you to discover and conjecture Linear Algebra concepts. The results are shown in the Figure 7 .

Figure 6: Question five in student survey [8].

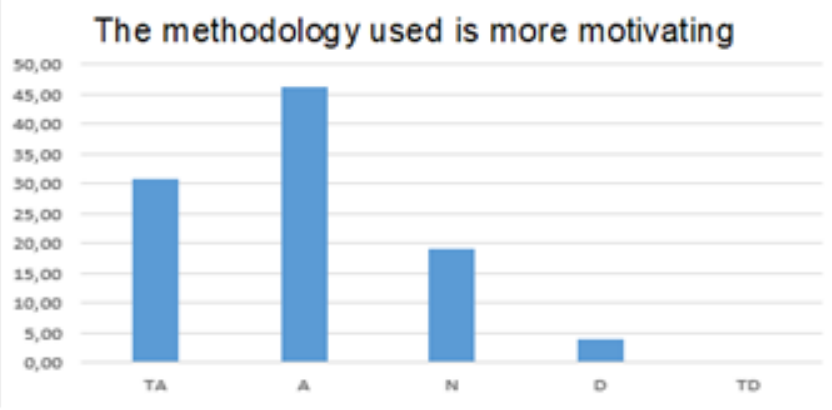

The results evidence that $100 \%$ of the students said they made or discovered conjectures about the concepts in class. These results are aligned with the results obtained in each one of the activities. 
Figure 7: Answers to question six from the final student survey [8].

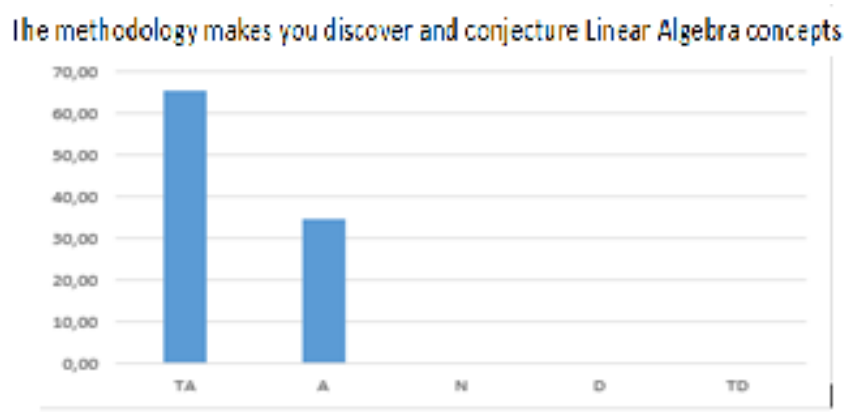

\section{- On the level of difficulty and the time to solve the problems}

The results for the level of difficulty and the time given for the development of these exercises are shown in the Figure 8.

100 believe that the time was enough to be able to develop the activities.

The guide for the interview was structured in the following manner:
1. How did you find the methodology of the course?

2. Which are the aspects you find more positive in this methodology?

3. Can you describe any problem or situation that has strongly called your attention?

4. What aspects could be improved in this methodological proposal?

5. What difference can you find between this methodology and the one offered by other mathematics courses you have taken at the University?

6. Which has been the contribution of this course to your education as an engineer?

In the interview, students showed the taste for the methodology of the course because it was dynamic, and said that the group work allowed them to interact and debate different viewpoints. One of the students said "not only we interact with the professor, the fact that we conjecture in groups is more exciting for the student".

In interview question number 1 , everyone said that the methodology is good, practical and dynamic, since the students are the center of the class.

Figure 8: Answers to questions 2 and 3 of the final students survey [8].

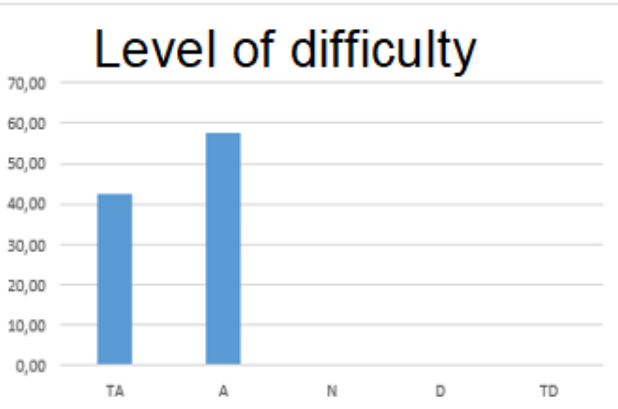

\section{Conclusions}

From the results obtained and from class observations one can conclude that implementing the didactic model based on plausible analysis, geometric visualization and use of technology:

1. Active learning has been furthered since the student is the center of this methodological proposal

2. The use of technology has motivated and facilitated learning since students use it as a tool both

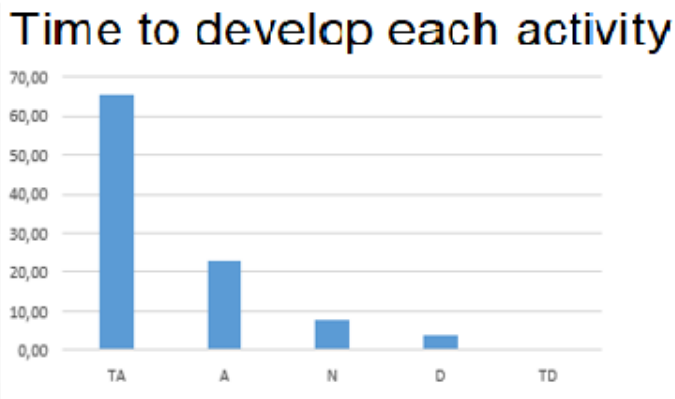

in visualization and in the routine procedure calculations

3. Non-routine, challenging problems motivate students to search solutions using different strategies that conduct them to learn the concept intended for each theme

4. Students' attitudes in class are always active since the methodology based on questions has them always looking for answers. 


\section{References}

[1] I. Lakatos, "Pruebas y refutaciones: la lógica del descubrimiento matemático", Madrid: Editorial Alianza, 1978.

[2] G. Polya, "Matemáticas y razonamiento plausible", Madrid: Editorial Tecnos, S. A., 1973.

[3] D. Carlson, C. Johnson, D. Lay and A. Porter, "The Linear Algebra curriculum study recommendations for the first course in Linear Algebra", The College Mathematics Journal, vol. 24, no. 1, 1993, pp. 41-46.

[4] J. Dorier, A. Robert, J. Robinet and R. Marc, "Teaching and Learning Linear Algebra in first year of French Science University", European Research in Mathematics Education, 1999.

[5] J. Dorier, "Teaching Linear Algebra at University", Proceedings of the ICM, Beijing, vol. 3, 2002, pp. 875-884.
[6] A. Sierpinska, "On some aspects of students' thinking in Linear Algebra", On the Teaching of Linear Algebra, pp. 209-246. https://doi.org/10.1007/ $0-306-47224-4+8$

[7] M. García and J. E. Nápoles, "A dialectical invariant for research in mathematics education", The Mathematics Enthusiast, vol. 12, no. 3, 2015, pp. 465-479.

[8] O. García, "Aprendizaje del álgebra lineal centrado en el razonamiento plausible en carreras de ingeniería", XVI Congreso de enseñanza y aprendizaje de las matemáticas, 2017, pp. 1-10.

[9] M. Cruz, "Definición de modelo didáctico", Holguín, Cuba, 2010.

[10] J. Strang, "Álgebra lineal y sus aplicaciones", México D.F:Editorial Thomson, 2007. 